\title{
Chemical use in farming and its health and environmental implications in a rural setting in southern India
}

\author{
Rakesh PS, Ankita P, Annie M Cherian, AshutoshMasih, Edwin Mohan, Geethu \\ Rachel, Goutham Sunny, Jayajiwan Simon, John T George, Kevin John, \\ Priyanka Schilling, Karpe M Lombi, Reginald Alex, Vinohar Balraj, \\ Venkata Raghava Mohan \\ (Department of Community Health, Christian Medical College, Vellore 632004, Tamil Nadu, India)
}

\begin{abstract}
Inappropriate use, handling and disposal of agrochemicals could have adverse health and environmental impact.This study was done in selected villages of a rural developmental block in Tamilnadu with the main objectives of assessing the knowledge and practices regarding storage, handling and disposal of routinely used agrochemicals; exploring the farmers' perceptions of agrochemical use and its potential ill effects on health and to determine if commonly used agrochemicals have reached the water consumed by the local population. Methodology involved cross sectional survey, focus group discussions, key informant interviews and water sample testing. Of the 98 farmers interviewed $18.4 \%$ stored agrochemicals in their homes prior to usage. Thirty nine percent used bare hands to mix the chemicals, a third disposed empty sacs or tins of agrochemicals in the open and $43 \%$ reused containers/sacks to store materials at homes. Only $28 \%$ used adequate personal protective equipment while applying agrochemicals. Focus group discussion and key informant interviews revealed that awareness regarding health effects of chemicals was poor among the farmers. Except for phosphorous, all chemicals tested were below detectable levels in the ground water samples from both the study villages. The practice of storing, mixing and applying agrochemicals without personal protection and unsafe disposal of pesticide containers appears to be widely prevalent in the study villages. A comprehensive program for creating awareness for safe management, handling and disposal of pesticides among both users and shop keepers is required to address this important health and environmental problem
\end{abstract}

Key words: agrochemicals, practices, pesticides, personal protective equipments, water contamination.

\section{Introduction}

Agriculture remains the principal source of livelihood for majority of the population in India. ${ }^{1}$ The increased use of synthetic fertilizers and chemical pesticides in agriculture started in India since 1960s as part of the Green Revolution. ${ }^{2}$ Over the past five decades synthetic fertilizers' consumption has drastically increased several foldsand India is now one of the leading producers of agrochemicals in the world. ${ }^{3,4}$

Many of the chemical pesticides can have harmful effects on human beings either as acute or chronic toxicity. ${ }^{5}$ Acute exposure to pesticides can lead to death or serious illnesses. ${ }^{6}$ About 355,000 people die globally each year due to unintentional acute poisonings. ${ }^{7}$ Two-thirds of these deaths occur in developing countries where such poisonings are associated with excessive exposure and or inappropriate use of toxic chemicals and pesticides present in occupational and domestic environments. ${ }^{8,9}$ The cumulative health impacts of human exposures to various agrochemicals can be a factor in a range of chronic health conditions and diseases likecancer, reproductive, endocrine, immunological, congenital and developmental disorders. ${ }^{10-13}$

Groundwater is the major source of drinking water in India. ${ }^{14}$ Besides, it is an important source of water for the agricultural and the industrial sector. The continued use of chemicals in agriculture has revealed its potential to percolate and reach the groundwater. ${ }^{15,16}$ There are four major routes through which pesticides reach the ground water. They may drift outside the intended area when sprayed, may percolate, leach or seep through the soil, may be carried to surface water as runoff. ${ }^{17}$ Factors that affect a pesticide's ability to contaminate water include its water solubility and half life, the distance from an application site to a body of water, weather, type of soil, presence of a growing crop and the method used to apply the chemical ${ }^{18}$ Once in ground water, pesticides and their degradation products can persist for years, depending upon the chemical structure of the compounds and environmental conditions. ${ }^{19}$

Good management, use, and disposal of agrochemicals is an important health and environment issue in developing countries. ${ }^{20}$ Safe pesticide management is essential to the well being of all those involved with using pesticides. The total exposure of a person to pesticide is the sum of all exposures resulting during different working situations like mixing, applying, storing or disposing the chemicals. ${ }^{21}$ Exposure to pesticides and there by its health impacts can be minimized at community level by appropriate and judicious use of agrochemicals, 
adopting recommended methods of mixing, applying, storing, disposing and practicing use of proper personal protective equipments (PPE). ${ }^{22,23}$

This study was done in selected villages of Kaniyambadi block of Vellore district in Tamilnadu to study the knowledge and practices regarding storage, handling and disposal of routinely used pesticides and fertilizers (agrochemicals). The farmers' perceptions of agrochemical use and health effects were also explored. This study also intended to determine whether the commonly used agrochemicals for agricultural purposes had reached the ground water. This information was thought to be useful to make informed policy decisions for bringing about changes in the agricultural practices to reduce the risk of exposure to harmful agrochemicals.

\section{Methods}

This study was done in two villages of Kaniyambadi block of Vellore district, selected for its availability of water for farming or the lack of it. Keelarasampet has a population of 2189 and most of the people depend on agriculture as their primary source of income. The village has a natural and continuous water source because it is located close to a river where rain water from the hills close by flows. Allivaram is another village which is on a higher ground and has a population of 1356 where water supply is relatively scarce and hence agriculture is seasonal.

Methodology included a survey using a structured questionnaire among farmers from both the villages, two focus group discussions (FGDs) and two key informant interviews. Three liters of water samples from three bore wells which constituted the main drinking water supply of these villages were collected; two from the agricultural village, and one from the non-agricultural village and tested in an accredited laboratory for presence of the commonly used agrochemicals in the study area which included phosphorous (as phosphate), urea (as nitrate), hexaconazole, carbendazim, lambda-chylothrin, monocrotophos, endosulfan (as alpha, beta and sulfate). The questionnaire included basic demographic information, commonly used pesticides and fertilizers, practice of mixing, storing and disposal of chemicals, re-use of containers, sacks and use of personal protective equipments. The questionnaire was translated into vernacular, back translated and piloted, modifications made before use. Farmers from both villages were selected by systematic random sampling from every third house, interviewed at their home using the questionnaire. Data was entered using Epi-info 2002, version 3.5.1 and was analyzed using software SPSS 12(SPSS Inc., 1989-2003) for windows.

A focus group guide was developed, the key themes for FGDs were identified as commonly used agrochemicals in that region, reasons for using it, harmful effects of these chemicals and ways to reduce the harmful effects. One FGD was conducted in each village with farmers who were currently involved in agriculture. The participants for FGD were selected with the help of the 'Health Aide', who is the village level trained worker. FGDs were held at the villages itself and the sites were chosen according to ease of access for the participants. Both FGDs were moderated by the same researcher, who ensured that each item on the agenda was fully discussed and that all the respondents had sufficient opportunity to express their views. The objectives of the study and implications of participation were explained to the group at the start.Demographic characteristics such as age and experience in agriculture were collected from the participants. After obtaining consent from each participant, the discussions were videotaped.FGD was analyzed on the same day in which it was conducted. The transcripts were translated to English by two researchers separately and correlated with the video recording. Themes were divided into common pesticides and fertilizers used, reason for using it, harmful effects, precautions taken to minimize harmful effects and were coded with different alphabets. Repeated themes were marked as important with a bold alphabet in red font color. All the flagged statements were put together and synthesized. Themes which evoked spontaneous discussions, themes which had more time spent on them and those themes associated with strong emotional cues were quoted verbatim.

Key informant interviews were conducted with an experienced farmer and with the inventory of the pesticide shop in the agricultural village. The interview focused on commonly used agrochemicals in the villages and trends in its usage over years.

\section{Results}

A total of 98 farmers were interviewed; 68 from Keelarasampet and 30 from Allivaram. The demographic characteristics of the farmers interviewed are shown in Table I. Mean age (SD) of the farmers interviewed was 47.3(12.1) years. Among them $18.7 \%$ (18/98) were illiterate and 47.9\% (47/98) owned less than one acre of land.

All used synthetic fertilizers and chemical pesticides for cultivation. Of them $18.4 \%$ (18/98) said they stored agrochemicals prior to use while a majority of them would buy the chemicals only before use. Eight $(8.2 \%)$ stored chemicals inside their house.

About 31.6\% (31/98) of the farmers interviewed, mixed chemicals at their household premises before taking it to the field for application. Among them, 38.8\% (38/98) mixed chemicals with bare hands while $41.8 \%$ (41/98) used a stick or ladle for mixing. 
Of those interviewed, $32.7 \%$ (32/98) threw away the empty sacks or tins of pesticides or fertilizers once empty, while $42.8 \%$ (41/98) reused it to store things; $12.2 \%$ (12/98) reported that they use empty sacks for storing grains. The common practices on the use of chemicals are summarized in Table 2.

A majority $73.5 \%(72 / 98)$ would not bathe or clean themselves with water immediately after applying pesticides. PPEwere used by $27.6 \%$ (27/98) while 18.4\% (18/98) did not use any personal protective equipment. Education of the farmer for less than 8 years was identified as a risk factor for not using any PPE with an adjusted odds ratio of 3.32 (95\% CI 1.12-13.2). The results of analysis of factors associated with use of PPE are presented in Table 3.

The commonly used pesticides in the study villages were monocrotophos, endosulfan, lambdachylothrin, diathone M45, hexaconazole, borate and carbendazim. The pesticides were classified using the World Health Organization (WHO) classification of pesticides based on hazard and is shown in Table IV. The major findings from the two FGDs showed that the practice of using chemicals in agriculture started in both the villages thirty years ago. Most of the people did not have adequate knowledge regarding the recommended amount of pesticides or fertilizers to be used. The local pesticide/fertilizer shop-keeper advised most of the farmers on the type and quantity of the chemicals to be used. All agreed that crop production had definitely increased since they started using chemical pesticides. Non availability of leaves from the forest due to restricted entry into the forest was a reason stated for using chemical fertilizers. Use of chemical pesticides for deliberate self-harm was discussed and was pointed as a major reason for not storing chemicals in their home along with the presence of children at homes The overall awareness regarding the effects of chemicals in causing chronic toxicity was poor in both the groups. Infertility among cattle was attributed to pesticide use which was agreed by many. Soil fertility was thought to decrease by the use of chemicals. One group felt that chemicals can reach ground water. Biological pesticides were considered as being "very mild", "not so effective" with "delayed effects. Organic farming and simultaneous chemical use were considered as bad since pests from the chemical farms would move to the organic farms. Avoiding spraying during rainy seasons, not letting the cattle to graze immediately after spraying, not storing pesticides at home were some of the ways by which the community suggested to reduce the harmful effects of pesticides. Personal protective equipment were not considered as being effective and a stated reason for not using it was they were not in the habit of using it. Few verbatim accounts from the FGDs are shown in Box 1.

All the pesticide compounds tested in the three water samples collected were below the detectable levels while phosphorus sample from a bore well in agricultural village was found to be 0.2 parts per million.

\section{Discussion}

The Insecticides Act, 1968 and Insecticides Rules, 1971 regulate the import, registration process, manufacture, sale, transport, distribution and use of insecticides and pesticides with a view to prevent risk to human beings or animals and for all connected matters, throughout India. ${ }^{24}$ However, the various act/welfare schemes applicable to agricultural workers have not been able to adequately protect and safeguard the interests of the workers.

The current study revealed poor awareness regarding the harmful effects of agrochemicals among the farmers. The practice of storing, mixing and applying agrochemicals without personal protection and unsafe disposal of pesticide containers appears to be widely prevalent in the study villages. The farmers mainly depend on the information from the shop owner regarding the type and amount of agrochemicals to be used.

The use of PPE while handling pesticides was low in the study villages. Only one in four farmers used to practice PPE adequately. Experience form elsewhere in India has shown similar findings. ${ }^{25-27} \mathrm{~A}$ comprehensive program for creating awareness for safe management, handling and disposal of pesticides/containers among both users and shop keepers is required to address this important health and environmental problem. Education activities should focus on increasing awareness regarding need for using proper personal protective measures among farmers while handling agrochemicals and these activities need to be continuous and ongoing. Block agriculture office should take an active responsibility to monitor the use of PPE among farmers.

Monocrotophos which is classified as "highly hazardous" and endosulfan, lambda chylothrin and diathon-M45 which are 'moderately hazardous', according to WHO recommended classification of pesticides by hazard, were widely used in the study villages. ${ }^{28}$ Food and Agriculture Organization recommends that WHO Ib (Highly hazardous) and class II (Moderately hazardous) pesticides should be avoided for regular use. ${ }^{29}$ Most class-I and II pesticides are banned or strictly controlled in the regulated industrialized world, but in India, where there are no resources to ensure safe use of pesticides, still class-I and II pesticides are produced and are freely available. ${ }^{30}$ Documented harm from endosulfan spraying in the Indian States of Kerala and Karnataka, the Supreme Court had to intervene and ban the pesticide throughout the country in May 2011. Many countries around the world like Brazil, Germany, Mexico and Benin have demonstrated that crops with good yield can be grown without the use of endosulfan or similar chemicals and Srilanka has demonstrated that after the 
endosulfan ban, yield has not dropped and there has been a large reduction in fatal poisonings. ${ }^{30-33}$ Advocacy is needed for reducing reliance on harmful chemical pesticides and encouraging the use of non-chemical alternatives and the less harmful pesticides and the use of pest-resistant genetically modified seeds through community involvement and participation in decision making are needed. Civil and medical societies have a major role to play in bringing evidence informed policy decisions.

The presence of organochlorine and organophosphorous pesticides in the ground water was detected from various places in India. ${ }^{34-36}$ The agrochemical compounds tested were below detectable level in the ground water samples, in the study area. Leaching of pollutants to groundwater is a complex process influenced by many other factors such as rainfall and temperature, soil properties like particle size distribution and organic carbon content, water solubility and half life of pesticides, the distance from an application site to a body of water, presence of a growing crop and the methods used to apply the chemical. ${ }^{18}$ The Partition Coefficient (PC) value of the pesticides, defined as the ratio of the pesticide bound to soil particles to the pesticide dissolved in the soil water, is another factor determining its potential to reach ground water. Knowing PC and half life, the pesticides can be classified based on their ground water contamination potential in to low, moderate and high. ${ }^{19}$ Among the chemical compounds tested in the study area, endosulfan and lambda-chylothrin have moderate potential and while all others have low potential to reach ground water. We tested for the chemical compounds in its original form rather than their degradation products. Hence it would be difficult to comment on the results of the ground water testing without considering these factors. Long-term and consistent data for assessing trends is essential for tracking water-quality response to changes in pesticide use and management practices and for providing early warning of unanticipated problems.

Some issues raised in this paper, though not exhaustive, indicate the scope for further research that is needed for the detailed analysis of pesticide use, externalities and policies in India. The country needs to enact a policy and enforce it, which promote safe pesticide practices among the farmers. National level initiative to provide information to community, dissemination of appropriate information regarding correct application of pesticides as well as intensive training on selective application of right pesticide at right time for the right pest, is the need of the hour.

V. Tables

Table 1. Characteristics of the study population $(\mathrm{N}=98)$

\begin{tabular}{|lll|}
\hline Characteristics & Categories & Number $(\%)$ \\
Age groups & $<30$ years & $2(2.1)$ \\
& $30-45$ years & $46(46.9)$ \\
& $46-60$ years & $43(43.8)$ \\
& $>60$ years & $7(7.2)$ \\
Educational status & Not attended school & $7(71.4)$ \\
& $1-5^{\text {th }}$ standard & $21(21.4)$ \\
& $5^{\text {th }}-10^{\text {th }}$ standard & $68(69.4)$ \\
& $>10^{\text {th }}$ standard & $2(2.1)$ \\
& & $18(18.7)$ \\
Literacy status & Illiterate & $47(47.9)$ \\
Land owned & $<1$ acre & $42(42.9)$ \\
& $1-5$ acre & $9(9.2)$ \\
\hline
\end{tabular}

Box 1. Verbatim accounts from focus group discussions

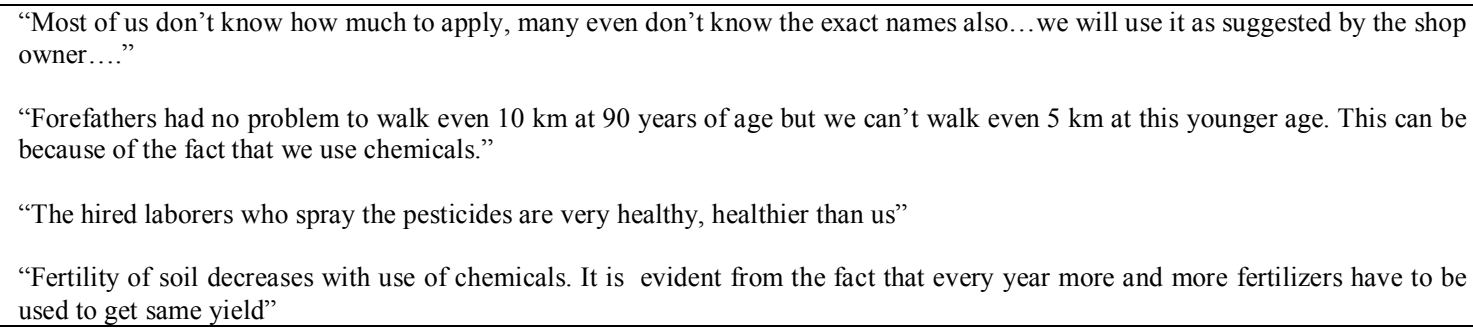


Table 2. Practices regarding use of chemicals in agriculture $(n=98)$.

\begin{tabular}{|c|c|c|}
\hline Activities & Categories & Number (\%) \\
\hline Storage of agrochemicals. & Farmers who store pesticides/fertilizers. & $18(18.4)$ \\
\hline Place of mixing of chemicals. & Farmers who mix chemicals at their house & $31(31.6)$ \\
\hline \multirow[t]{4}{*}{ Method of mixing chemicals. } & Stick/ladle & $41(42)$ \\
\hline & Bare hand & $38(38.8)$ \\
\hline & Gloves & $16(16.3)$ \\
\hline & Others & $3(3.1)$ \\
\hline \multirow[t]{5}{*}{ Disposal of empty sacs/tins. } & Store materials & $42(42.8)$ \\
\hline & Thrown away & $32(32.7)$ \\
\hline & Buried & $11(11.2)$ \\
\hline & Burnt & $9(9.2)$ \\
\hline & Given to rag pickers & $4(4.1)$ \\
\hline \multirow{3}{*}{$\begin{array}{l}\text { Cleaning immediately after applying } \\
\text { chemicals. }\end{array}$} & Soap and water & $9(9.2)$ \\
\hline & Water & $17(17.3)$ \\
\hline & Won't do anything & $72(73.5)$ \\
\hline \multirow{6}{*}{$\begin{array}{l}\text { Personal protective equipments while } \\
\text { applying chemicals. }\end{array}$} & Gloves & $47(47.9)$ \\
\hline & Clothing & $60(61.2)$ \\
\hline & Mask & $80(81.6)$ \\
\hline & Shoes & $28(28.6)$ \\
\hline & All the four equipments & $27(27.6)$ \\
\hline & Won't use anything & $18(18.4)$ \\
\hline
\end{tabular}

Table 3. Factors associated with use of Personal protective equipments

\begin{tabular}{|lllllll}
\hline Character & Categories & $\begin{array}{l}\text { Not using any } \\
\text { PPE }\end{array}$ & $\begin{array}{l}\text { Using at least } \\
\text { one PPE }\end{array}$ & p value & $\begin{array}{l}\text { Odds ratio (95\% } \\
\text { CI) }\end{array}$ & $\begin{array}{l}\text { Adjusted OR } \\
(95 \% \text { CI) } \\
\text { Multivariate } \\
\text { analysis }\end{array}$ \\
Age & $>45$ years & $10(19.6 \%)$ & $41(80.4 \%)$ & 0.473 & 1.05 \\
& $<=45$ years & $8(17 \%)$ & $39(83 \%)$ & & $(0.42-3.42)$ \\
Literacy & Illiterate & $5(27.8 \%)$ & $13(72.2 \%)$ & 0.206 & 1.98 \\
& Literate & $13(16.3 \%)$ & $67(83.8 \%)$ & & $(0.61-6.51)$ \\
Land & $<=1$ acre & $10(21.3 \%)$ & $37(78.7 \%)$ & 0.325 & 1.45 \\
owned & $>1$ acre & $8(15.7 \%)$ & $43(84.3 \%)$ & & $(0.52-4.06)$ \\
Education & $<=8^{\text {th }}$ grade & $13(27.7 \%)$ & $34(72.3 \%)$ & 0.021 & $3.51 *$ \\
& $>8^{\text {th }}$ grade & $5(9.8 \%)$ & $46(90.2 \%)$ & & $(1.14-10.81)$ \\
\hline
\end{tabular}

*significant odds ratio

Table 4. Classification of commonly used pesticides in the study villages by hazard ${ }^{24}$

\begin{tabular}{|ll|}
\hline Chemical name of pesticide & WHO classification by hazard \\
Monochrotophos & Ib ( highly hazardous) \\
Endosulfan & II (moderately hazardous) \\
Lambda chylothrin & II(moderately hazardous) \\
Diathon M45 & II(moderately hazardous) \\
Hexaconazole & III (slightly hazardous) \\
Borate & III(slightly hazardous) \\
Carbendazim & U ( not hazardous) \\
\hline
\end{tabular}

\section{Conclusion}

The practice of storing, mixing and applying agrochemicals without personal protection and unsafe disposal of pesticide containers appears to be widely prevalent in the study villages. A comprehensive program for creating awareness for safe management, handling and disposal of pesticides among both users and shop keepers is required to address this important health and environmental problem

\section{References}

[1] Department of Agriculture and Cooperation, Ministry of Agriculture.Annual report,2010-2011.New Delhi: Government of India; March 2011

[2] Roy BC, Chattopadhyay GN.Greenpeace India.Subsidising Food Crisis.[Internet]. Available from: http://www.greenpeaceindia, accessed on January 20,2012

[3] Food and agricultural division,United Nations. Fertilizer use by crop in India.Rome: FAO; 2005 
[4] Corporate catalyst India.Surveys and reports.Chemical and petrochemical industry; 2011[cited on Jan 2012]. Available from:http://www.cci.in/pdf/surveys_reports/chemical-petrochemical-industry.pdf

[5] U.S. Environmental Protection Agency. Pesticides health and safety. Human health issues [Internet]. Available from: http://www.epa.gov/pesticides/health/human.htm, accessed on January 21,2012

[6] World Health Organization. Public health impact of pesticides used in agriculture. Geneva; 1990

[7] World Health Organization. The World health report 2003 - shaping the future. Geneva; 2003

[8] Goldman L, Tran N. Toxics and poverty: the impact of toxic substances on the poor in developing countries. Washington DC: World Bank; 2002

[9] FAO/UNEP/WHO. Childhood pesticide poisoning: information for advocacy and action. Geneva: United Nations Environment Program; 2004

[10] Sanborn M, Kerr KJ, Sanin LH, Cole DC, Bassil KL, Vakil C. Non-cancer health effects of pesticides: systematic review and implications for family doctors. Can Fam Physician 2007; 53 (10):1712-20. Cited in PubMed;PMID:17934035

[11] Jurewicz J, Hanke W. Prenatal and childhood exposure to pesticides and neurobehavioral development: review of epidemiological studies. Int J Occup Med Environ Health 2008; 21 (2): 121-32. Cited in PubMed; PMID:18614459

[12] United Nations Development Program. Human development report - consumption for human development. New York: Oxford University Press; 1998.

[13] Yáñez L. Overview of human health and chemical mixtures: problems facing developing countries. Environmental Health Perspectives 2002; 110 (6): 901-9. Cited in PubMed; PMID:12634117

[14] Central Ground Water Board, Ministry of Water Resources. Dynamic Ground Water Resources of India. New Delhi: Government of India; 2006

[15] Francisco SB, Baskaran S, Kennedy RI. Ecological relative risk (EcoRR): another approach for risk assessment of pesticides in agriculture. Agriculture,Ecosystems and Environment 2002; 91(1-3):37-57

[16] Singh SK, Raha P, Banerjee H. Banned OrganochlorineCyclodiene Pesticide in Ground Water in Varanasi, India. Bull.Environ.Contam.Toxicol 2002; 76: 935-41.Cited in PubMed; PMID:16855898

[17] US Geological Survey. Water Science for Schools. Pesticides in Groundwater. [Internet] 2012 [updated 2012 Mar 9; cited 2012 Apr 28]. Available from: http://ga.water.usgs.gov/edu /pesticidesgw.html

[18] Kellogg RL, Nehring R, Grube A, Goss DW, and Plotkin S. Environmental indicators of pesticide leaching and runoff from farm fields. Washington: United States Department of Agriculture; 2000.

[19] Thomas JB. Pesticides and Groundwater. Pesticides as potential pollutants. Doug Peterson, editor. Land and Water; 1988

[20] Health and Environment Linkage Initiative, WHO. Toxic hazards.[Internet] 2012 [cited on 2012 April 26]. Available from: http://www.who.int/heli/risks/toxics/chemicals/en/

[21] Antonella Fait, Bent Iverson, Manuela Tiramani, Sara Vaisantin, Macro Marconi.Preventing health risk from the use of pesticides in agriculture. Protecting workers health series. Geneva: World Health Organization; 2001

[22] World Health Organization Pesticide Evaluation Scheme. Technical guidance for management of public health pesticides. Geneva: WHO; 2010

[23] Food and Agricultural Organization How to Reduce Risks to Human Health and the Environment. [Internet] 2010 [cited on 2012 April 25]. Available from: http://www.fao.org/ag/locusts-CCA/en/1102/1123/index.html

[24] Public law: Insecticide act 1968, Act No.46 of 1968 ( $2^{\text {nd }}$ September 1968)

[25] Singh B,Gupta MK.Pattern of use of personal protective equipments and methods during application of pesticides by agricultural workers of rural areas of Ahmednagar district.Indian J Occup Environ Med 2009;13(3):127-30.

[26] Chitra GA, Muraleedharan VR, Swaminathan T, VeeraraghavanD.Use of pesticides and its impact on health of farmers in South India. Int $J$ Occup Environ Health 2006; 12:228-33. Cited in PubMed; PMID:16967829

[27] Bhardwaj DN, Dogra TD, Singh B, Reddiah VP, Kulshrestha S.Study of deficiencies in pesticides spraying \&safety equipment in rural India. Medico-legal update 2004; 4 (4):116-7

[28] World Health Organization. The WHO recommended classification of pesticides by hazard and guidelines to classification. Geneva: WHO; 2004

[29] Pesticide Action Network,United Kingdom.The lists of lists. $3^{\text {rd }}$ ed. London: PANUK; 2009

[30] Robert Mensah, DavoVodouhe and Damien Sanfilippo. A new tool for Africa's organic cotton growers. Pesticides News 2008 ; 79

[31] Fernando Bejarano González. El endosulfán y susalternativas en América Latina. International POPs Elimination Network 2009.

[32] Susan Haffmans. Phasing in alternatives to endosulfan- Reasons, experiences and links. Hamburg: PAN Germany; 2008

[33] Manuweera G, Eddleston M, Egodage S, Buckley NA. Do targeted bans of insecticides to prevent deaths from self-poisoning result in reduced agricultural output? Environ Health Perspect 2008; 116 (4): $492-5$.

[34] NaliniS,Ajit Kumar S, RashmiS.Organochlorine and organophosphorous pesticide residues in ground water and surface waters of Kanpur, Uttar Pradesh, India.Environ Int 2005; 31( 1): 113-20. Cited in PubMed; PMID:15607785

[35] Irani Mukherjee, MadhubanGopal. Organochlorine Insecticide Residues in Drinking and Ground Water in and Around Delhi. Environ Monit Assess2002; 76(2); 185-193. Cited in PubMed; PMID:12108591

[36] Jayashree R, Vasudevan N. Organochlorine pesticide residues in ground water of Thiruvallur district, India.Environ Monit Assess 2007; 128(1-3):209-15. Cited in PubMed; PMID: 17016752 